\title{
Desenvolvimento dos Sistemas de Vigilância Epidemiológica da Varíola e da Poliomelite: A Transformação de Conceitos em Categorias Operacionais
}

\section{The Development of Epidemiological Surveillance Systems for Smallpox and Poliomyelitis: Changing Concepts in Operational Categories}

\author{
José Fernando de S. Verani ${ }^{1}$ \\ Eduardo P. Maranhão ${ }^{1}$ \\ Fernando Laender ${ }^{1}$
}

\section{VERANI, J. F. S.; M ARA NHÃ O,E.P.\& LAENDER, F. The Development of Epidemiological Surveillance Systems for Smallpox and Poliomyelitis: Changing Concepts in Operational Categories. Cad. Saúde Públ., Rio de Janeiro, 9 (1): 28-38, jan/mar, 1993.}

This article describes the process by which some concepts of epidemiological surveillance are elaborated and turned into operational categories to comprise the so-called epidemiologial surveillance system for two specific diseases. The authors describe some epidemiological concepts and categories which were elaborated over the course of the smallpox eradication program and more recently in the poliomyelitis eradication program. Such concepts and categories as outbreak containment, cross-notification, and case definitions are described as they fit into a series of actions which make up the epidemiological surveillance system. Finally, it is worth noting that the description developed in this article is based on personal observations, since the authors participated in the smallpox eradication program in Bangladesh and Somalia as well as in the regional poliomyelitis eradication program in the A mericas..

Keywords: Epidemiological Surveillance; Vaccination; Poliomyelitis; Smallpox; M op Up; Epidemiology

\section{INTRODUÇÃO}

Os sistemas de vigilância epidemiológica da varíola e da poliomielite foram sendo desenvolvidos à medida que sua prática exigia respostas a situações concretas, em vista dos avanços que se fazia, e que se faz no conhecimento da epidemiologia das doenças. O fato da transmissão da varíola se dar através do contato direto entre um caso e uma pessoa não-imunizada, possibilitou o desenvolvimento do conceito de bloqueio, associando-se à constatação de que a vacinação indiscriminada não evitava, necessariamente, a transmissão do vírus.

\footnotetext{
${ }^{1}$ Departamento de Epidemiologia e Métodos Quantitativos em Saúde da Escola Nacional de Saúde Pública. Rua Leopoldo Bulhões, 1480, $8^{\circ}$ andar, 21041 210, Rio de Janeiro, RJ, Brasil.
}

De fato, em algumas áreas, durante os anos 70, a persistência da transmissão do vírus da varíola desafiou as práticas de vacinação convencionais, fossem elas de rotina ou campanhas. Do mesmo modo, o surto de poliomielite ocorrido no Nordeste do Brasil a partir de janeiro de 1986 parece confirmar que os "bolsões" de suscetíveis podem possibilitar a reprodução do vírus em níveis dificilmente detectáveis pelo sistema tradicional de vigilância epidemiológica. Se, por um lado, a detecção destes surtos de formas paralíticas da infecção não tem alcançado uma extensão que possibilite interferir na cadeia de transmissão do vírus, a demarcação epidemiológica da extensão de cada surto precede e condiciona os métodos e estratégias de controle da transmissão — isto é, o próprio conceito de bloqueio.

Em ambas as situações — tanto no Programa 
da Varíola quanto no da Poliomielite - o conceito de bloqueio é determinado pelas características clínico-epidemiológicas das doenças.

No Programa da Varíola utilizava-se algumas destas características, como, por exemplo, tempo de incubação da doença, para se determinar o tempo de duração do bloqueio de um determinado surto. Algumas características da poliomielite, como infecção sem manifestação clínica, na maioria das vezes não permitem estabelecer o ponto na cadeia de transmissão em que um suscetível foi exposto ao vírus. Isto faz com que o conceito de bloqueio seja ampliado e bastante diferenciado do conceito utilizado no Programa da Varíola.

O importante é que, no momento em que os conceitos são elaborados, tem lugar um processo em que tais conceitos são transformados em categorias operacionais.

A pronta detecção de casos suspeitos - pacientes com erupção e febre -, possibilitada pela longa experiência clínica da varíola, tornou possível, portanto, estabelecer várias categorias operacionais que permeiam o programa, possibilitando, assim, medir e monitorar sua eficácia. Como veremos, algumas dessas categorias, que, repetimos, são operacionais, porém derivadas de um conhecimento da epidemiologia da doença - são redefinidas a partir do momento em que tem início o Programa de Erradicação da Poliomielite.

Não cabendo no âmbito deste trabalho discutir as implicações teóricas de "sistema", devemos, não obstante, deixar claro o que entendemos aqui por sistema de vigilância epidemiológica.

Entendemos que um sistema necessita normas, métodos e - característica importante ações regulares e repetidas, ou, no jargão sociológico, rotinizadas. A existência de normas definidoras de caso, de contato, de período de incubação, de imunidade, entre outros, permite caracterizar um conjunto articulado no que chamamos de normas de um sistema. Um fluxo de informações preciso e oportuno, acionando ações rotinizadas de acordo com aquelas normas, permite também caracterizar entradas e saídas do sistema.

Descreveremos como tais elementos se conju- gam durante a erradicação da varíola para constituir o Sistema de Vigilância Epidemiológica, analisando tal sistema no momento atual da erradicação da poliomielite.

\section{DE CONCEITOS EPIDEMIOLÓGICOS A CATEGORIAS OPERACIONAIS}

As primeiras categorias que trataremos de apresentar aqui são aquelas que dizem respeito à detecção, o mais cedo possível, de um caso, levando, assim, à caracterização de um surto e ao seu conseqüente controle.

\section{O Conceito de Caso de Varíola}

Um caso de varíola, no sentido clássico, era definido como doença com erupção e febre, de evolução exantemática com fases bem marcadas e associada à presença do vírus da varíola. Um caso podia ou não estar associado a um surto localizado, podendo ser um caso índice ou um caso secundário, pertencente a uma segunda geração de casos de um mesmo surto.

A sintomatologia da varíola, como dizíamos anteriormente, na maioria das vezes facilitava a sua detecção na maioria das vezes. Exceção feita a casos modificados, não-típicos quanto à sua clínica, o aparecimento das primeiras pústulas colocava o paciente prontamente na rede de vigilância da doença. Isto é, um caso - e especialmente onde era endêmica a varíola maior - fazia com que a extensa sequiência de ações rotinizadas se concretizasse, acionando todo o Sistema de Vigilância Epidemiológica.

Exceções também para os casos em que, por força de padrões culturais milenares - como na Índia e em Bangladesh — , a detecção de um caso podia adiar o acionamento do sistema, mas apenas adiar, porque sempre era acionado.

Os métodos de detecção eram simples e acessíveis a pessoal leigo ou a pessoas das comunidades. Um dos métodos utilizados era a busca ativa de casos, que consistia em percorrer os conglomerados, fossem urbanos ou rurais, e apresentar uma foto de um caso típico de varíola, facilmente identificado, e perguntar por casos semelhantes àquele que tivessem ocorrido na localidade ou fora dela. Conseguia-se, assim, 
informações sobre casos suspeitos, ao menos com a presença de erupções. Imediatamente o sistema era acionado, passo a passo.

A primeira ação era investigar a informação de caso suspeito, localizando o paciente e procedendo ao exame clínico e à investigação epidemiológica. Dependendo do estágio da doença, colhia-se amostra para exame laboratorial - pus ou vesículas - procedendo-se ao envio da amostra ao laboratório de referência. Concomitantemente, iniciava-se o segundo passo: a ação de bloqueio do caso considerado provável (embora tal categoria não fosse tão decisiva como o é para a erradicação da pólio, como veremos mais adiante).

Neste quadro, uma equipe - ou várias, dependendo das extensões populacional e geográfica do surto em questão - era colocada em tempo integral para um período médio de duas gerações de casos - 40 dias - possibilitando, com isso a detecção de casos que ocorressem neste período e interrompendo, através das medidas de bloqueio, a transmissão do vírus.

Ações concomitantes eram realizadas em outras áreas que tivessem relação com o surto, no sentido de detectar qualquer possibilidade de elos epidemiológicos na cadeia de transmissão.

Tal possibilidade fazia acionar uma outra categoria: a de notificação cruzada, onde áreas possivelmente afetadas ou relacionadas com um dado surto pudessem também ser controladas, alcançando a ação de bloqueio extensões muito maiores do que o próprio surto em questão. A intensa migração populacional em Bangladesh deu exemplos típicos de tal ocorrência. Era freqüente a notificação cruzada de distritos longínquos em que era possível estabelecer uma relação epidemiológica entre surtos de varíola. A literatura assim o narra também em relação à Etiópia e à Índia.

Do ponto de vista epidemiológico, a demarcação da extensão dos surtos e o estabelecimento da "escala de controle" são os desafios atuais que se colocam ao esforço de erradicação da poliomielite. A circulação do vírus da varíola, empurrada por força das vacinações a esses "bolsões", encontrava condições não muito distintas da situação da poliomielite hoje, no que diz respeito à persistência da transmissão do vírus.
Se pensarmos que os três fatores fundamentais - vacina eficaz, agulha bifurcada e vigilância/bloqueio de surtos - que marcaram definitivamente a erradicação da varíola foram sendo desenvolvidos e experimentados ao longo do esforço de erradicação, podemos supor que a "perseguição" do poliovírus implicará o desenvolvimento e aperfeiçoamento de tecnologias e métodos que possibilitem a sua erradicação. Os surtos de poliomielite paralítica no Nordeste do Brasil em 1986 têm remetido os estudos e reflexões sobre estes dois planos - tecnologia e métodos de controle. Do mesmo modo, um surto na Colômbia, em 1991, não deixa dúvidas quanto à necessidade de se ampliar o conceito de bloqueio, já que a existência de bolsões de suscetíveis confirma que a vacinação convencional sozinha não é capaz de interromper a cadeia de transmissão.

No que diz respeito à tecnologia, é fundamental o estudo da qualidade da vacina utilizada, incluindo-se aí estudos soro-epidemiológicos. A vacina antipólio trivalente oral em uso no Brasil encontra-se dentro dos padrões de qualidade exigidos pela Organização Mundial da Saúde (OMS). Não obstante, a identificação do poliovírus tipo 3 em $71 \%$ dos casos no surto do Nordeste sugeriu a necessidade de estudos e observações em relação ao componente P3 da vacina trivalente, particularmente quando se contrasta estes dados com aqueles de 1985, onde o tipo 3 era responsável por $23 \%$ dos casos e o tipo 1 , por $72 \%$ dos casos. Constatou-se que, na formulação da Vacina Antipólio Oral (Oral Polio Vacine), o componente para o tipo 3 não continha partículas virais infectantes em número suficiente para produzir a imunização. Assim, alterou-se a formulação da vacina e o surto foi controlado, não se registrando casos adicionais.

Além disso, o fato da incidência do poliovírus 3 concentrar-se na região nordeste sugeriu a necessidade de se observar as condições da rede de frio na área afetada, já que os níveis do componente P3 da vacina, por serem mais baixos, estariam mais vulneráveis a oscilações térmicas. $\mathrm{O}$ estudo das condições de conservação das vacinas torna-se relevante quando se constata que $36 \%$ dos casos apresentam história vacinal de 3 doses ou mais com a vacina trivalente oral. 
Dados preliminares de uma pesquisa nãopublicada realizada no Nordeste em 1986 indicam que $50 \%$ das unidades sanitárias da amostra tinham condições satisfatórias de conservação das vacinas.

Em relação aos métodos de controle, a situação atual tem sugerido a necessidade de estudos que reflitam os níveis imunitários da população suscetível, bem como as estratégias para se alcançar coberturas em áreas de "bolsões" que possibilitem a circulação do poliovírus selvagem.

Neste aspecto, o desenvolvimento de sistemas de vigilância se impõe como a problemática mais crítica.

Nos últimos anos — a partir de 1986 —, à medida que os planos de erradicação da poliomielite foram sendo desenvolvidos, as modalidades de vigilância epidemiológica se adaptaram às características epidemiológicas do poliovírus selvagem.

Assim sendo, o programa assume, como estratégia básica a conjugação de métodos específicos de vigilância epidemiológica e a utilização maciça da vacina antipolio oral de vírus vivo atenuado.

O Sistema de Vigilânicia Epidemiológica da Poliomielite requer, pela especificidade do poliovírus, uma sensibilidade ampla, traduzida na detecção e notificação de casos de paralisia flácida aguda em menores de 15 anos.

Ao mesmo tempo, é necessário que haja uma maior especificidade da Vigilância Epidemiológica, traduzida no número de casos confirmados por isolamento de poliovírus selvagem nas fezes de pacientes acometidos de paralisia flácida aguda.

Sobre estes dois aspectos - sensibilidade e especificidade - desenvolveram-se indicadores do Sistema de Vigilância Epidemiológica que são Específicos para o Programa de Erradicação da Poliomielite, como veremos mais adiante.

\section{O Conceito de Caso de Poliemielite}

O conceito de caso de poliomielite, ao contrário do conceito de caso de varíola, supõe uma definição mais elaborada devido à complexidade clínica da doença. Se, por um lado, o diagnóstico inicial de suspeição pode ser feito com facilidade por pessoal não-especializado, por outro, ele pode trazer complicações para a sua confirmação, já que, por ser uma síndrome neurológica, o mesmo requer maior especialização.

Assim, introduziu-se no programa algumas subcategorias que tornassem possível a operacionalização da Vigilância Epidemiológica.

No contexto do programa de erradicação da transmissão autóctone do poliovírus selvagem, a definição de caso supõe, portanto, algumas variantes operacionais.

Um caso de poliomielite é definido, a partir de 1985, época em que é lançado o Programa de Erradicação na região das Américas, como:

\section{Caso Suspeito}

Um caso de paralisia aguda em qualquer pessoa menor de 15 anos, cuja origem não seja um traumatismo grave. (Esta classificação era provisória, devendo dentro de 48 horas passar para provável ou descartado.)

\section{Caso Provável}

Um caso de paralisia flácida aguda de origem indeterminada.

\section{Caso Confirmado}

Um caso provável com confirmação de:

- Laboratório;

- Nexo epidemiológico com outro caso;

- Paralisia residual decorridos 60 dias do início;

- Falecimento do caso provável.

Com o desenvolvimento do programa, de 1985 a 1990 assiste-se à diminuição drástica dos casos de pólio. A definição de caso torna-se mais abrangente - mais sensível - passando à detecção de casos de paralisia flácida aguda como condição de entrada no Sistema de Vigilância, ao passo que aumenta a especificidade ao longo das etapas de investigação, chegandose confirmação do caso através do isolamento do poliovírus selvagem.

Em 1990, o Grupo Técnico Assessor para a erradicação da pólio elabora as seguintes definições: 


\section{Poliomielite Confirmada}

Enfermidade paralítica flácida aguda associada ao isolamento de poliovírus selvagem.

\section{Poliomielite Vacinal}

Enfermidade paralítica aguda associada ao isolamento do vírus vacinal em pessoa que tenha recebido à OPV 30 dias antes da manifestação da doença e que não tenha sido exposta a OPV depois da manifestação dos sintomas.

\section{Poliomielite Compatível (ou Pólio Provável)}

Enfermidade paralítica aguda, com paralisia residual aos sessenta e cinco dias, ou morte, ou falta de acompanhamento, para a qual não existia pelo menos duas amostras de fezes, obtidas num prazo de das duas semanas após a manifestação dos sintomas, examinadas em três laboratórios.

Um estudo recente de Andrus et al. (1991), a partir das paralisias flácidas agudas notificadas na Américas entre 1989 - 1990, analisa a sensibilidade e a especificidade de alguns critérios operativos referentes à definição de caso da seguinte maneira:

“ El problema, a los efectos de erradicar la transmisión del poliovirus salvaje de las A mericas, en definitiva, del mundo, reside en que podamos distinguir los casos "verdaderos" de polio - los causados por el poliovirus salvaje - de los casos de parálisis flaccida aguda debidos a outras causas (...) para minimizar el uso ineficiente de los recursos limitados necessarios para la erradicación mundial de la polio, es imperioso contar con criterios operativos de tamizado que sin perder sensibilidad, hagan possible una mayor especificidad (...)" (Andrus et al., 1991).

Os autores identificam várias características de casos notificados de paralisia flácida aguda e, utilizando o método epidemiológico, concluem sobre as características mais fortemente associadas à paralisia flácida como prioritárias em relação às ações de controle (ver Tabelas 1 e 2).

Assim, as características idade menor de seis anos, febre e instalação da paralisia em menos de quatro dias, quando combinadas, permitem uma definição de caso de poliomielite com uma especificidade de $80 \%$.

No outro extremo, definir o caso tomando-se apenas a característica paralisia flácida tem uma especificidade nula. Isto traz conseqüências importantes para a Vigilância Epidemiológica, já que uma revisão de alguns casos sugere que a definição de categorias, como a de caso, pode estar associada a um maior período de pendência na investigação, retardando os mecanismos de bloqueio do surto. Numa revisão dos casos notificados no Brasil até a $43^{\mathrm{a}}$ semana do ano de 1987, no total do país, $48 \%$ encontravam-se na categoria "pendentes" — isto é, sem investigação conclusiva -18 meses após o início da investigação.

Comparativamente, os dados para 1990 refletem uma mudança qualitativa no conceito de caso, já que $84 \%$ dos casos notificados ocorreram num período de 15 dias a partir do déficit motor. Do mesmo modo, verifica-se que, na última semana epidemiológica de 1990, apenas 91 casos perma-neciam na categoria "pendentes" - aguardando confirmação laboratorial ou visitas finais. Os dados para 1991 e 1992 sugerem que a definição atual de caso permite uma investigação mais conclusiva dos casos notificados.

\section{Conceito de Bloqueio}

Os resultados de um inquérito domiciliar de cobertura vacinal realizado em Arapiraca, Alagoas, em 1986, sugerem que a estratégia de vacinação implementada não conseguiu atingir um contingente importante da população suscetível, no qual se concentram 53\% dos casos notificados: os grupos etários formados menores de 1 ano e por aqueles de 1 ano de idade, com coberturas vacinais de $24 \%$ e $36 \%$ respectivamente, se consideradas três doses da vacina oral (Opas/SNABS, 1986).

O fato do inquérito ter sido realizado depois de quatro campanhas de vacinação, durante o ano de 86, e o fato do Município em questão realizado duas operações de bloqueio podem sugerir que a definição de "bloqueio" não interferiu na manutenção de um estoque importante de "bolsões" de suscetíveis.

O desenvolvimento do conceito de "bloqueio", ao menos em seu sentido prático-opera- 
TABELA 1. Análise dos Critérios para a Investigação de Casos de PFA Américas, 1989-1990

\begin{tabular}{|c|c|c|}
\hline Critério $^{*}$ & $\begin{array}{c}\text { Sensibilidade } \\
(\%)\end{array}$ & $\begin{array}{c}\text { Especificidade } \\
(\%)\end{array}$ \\
\hline Paralisia Flácida Aguda & 100 & 0 \\
\hline Idade $<6$ a ou Instal $<4$ d & 100 & 5 \\
\hline Idade $<6$ a ou Febre ou Instal $<4 d$ & 100 & 7 \\
\hline Febre ou Instal $<4 \mathrm{~d}$ & 100 & 16 \\
\hline (Idade $<6$ a e Febre) ou & 100 & 19 \\
\hline Idade $<6$ a ou $($ Febre e Instal $<4 d)$ & 100 & 27 \\
\hline (Idade $<6$ a e Instal $<4$ d) ou Febre & 100 & 34 \\
\hline Idade $<6$ a ou Febre & 97 & 23 \\
\hline Idade $<6$ a e (Febre ou Instal < 4d) & 96 & 48 \\
\hline Idade $<6$ a e Instal $<4 d$ & 90 & 51 \\
\hline (Idade $<6$ a ou Instal $<4 d$ ) e Febre & 74 & 61 \\
\hline Idade $<6$ a e Febre & 70 & 70 \\
\hline Febre e Instal $<4 d$ & 67 & 68 \\
\hline Idade $<6$ a e Febre e Instal $<4 d$ & 63 & 80 \\
\hline
\end{tabular}

Fonte: OPS

* Três fatores estudados: idade $<6$ anos, presença de febre ao início da paralisia, menos de 4 dias para a instalação da paralisia.

Nota: $\mathrm{A}$ análise se limitou àqueles casos que tinham informação.

cional, tem uma trajetória semelhante com o correr do Programa de Erradicação da Varíola.

Assim, o modo de transmissão da doença homem/homem em contato direto, através das vias respiratórias ou do contato com lesões de pacientes, além de fatores epidemiológicos tais como período de incubação - determinou a especificidade do bloqueio, no caso da varíola.

Com o advento da erradicação da transmissão autóctone do vírus selvagem da poliomielite, faz-se necessário, hoje, ajustar o conceito de bloqueio às características epidemiológicas da doença. E é este, no momento, um dos pontos mais cruciais nas ações de erradicação da poliomielite.

O Grupo Técnico Assessor do Programa Ampliado de Imunizações/Erradicação da Pólio, da OPS, vem discutindo o assunto, numa tentativa de se chegar a uma definição operacional de "bloqueio". Recomenda-se, hoje, que qualquer área em que haja um caso provável de poliomielite deve ser objeto de uma ação de bloqueio, esto é, que uma extensa área em torno do caso seja completamente vacinada/revacinada.

Numa área urbana, por exemplo, as ações devem abranger toda a cidade, ou, pelo menos, o núcleo urbano da área em questão. Em cidades maiores, no entanto, o bloqueio pode não atingir todo o núcleo urbano, mas restringir-se a determinados bairros.

Em se tratando de área rural, os núcleos populacionais imediatamente próximos ao caso devem ser vacinados completamente.

No entanto, tais definições não são tão facilmente absorvidas pelo pessoal da rede de saúde a nível local. Em algumas áreas, o que se tem entendido a nível local é que, no caso de uma 
TABELA 2. Características dos Casos de PFA por Vírus Selvagem e por Outras Causas de PFA Américas, 1989-1990

\begin{tabular}{lccrc}
\hline \hline Característica & Selvagem $^{*}$ & Outras $^{* *}(\%)$ & OR $^{* * * *}$ & $\mathrm{P}$ \\
\hline Idade < 6 a. & $35(92)$ & $2464(58)$ & 8,3 & $<0,0001$ \\
Febre & $25(76)$ & $756(45)$ & 3,7 & $=0,001$ \\
Instalação & $27(93)$ & $2182(46)$ & 15,8 & $<0,0001$ \\
Nervos Craniais & $03(15)$ & $807(44)$ & 0,22 & 0,02 \\
Seqüela & $23(83)$ & $814(33)$ & 9,3 & $<0,0001$ \\
Atrofia & $10(71)$ & $325(16)$ & 10,4 & $<0,0001$ \\
Assimetria & $15(52)$ & $523(20)$ & 4,2 & $<0,0001$ \\
\hline \hline
\end{tabular}

Fonte: OPS, dados preliminares.

* Selvagem - casos confirmados associados com vírus selvagem.

** Outros - todas as outras causas de PFA.

A análise está limitada a casos com informação.

As características apresentadas são: idade $<6$ anos, febre ao início da paralisia, tempo de instalação $<4$ dias, nervos craniais afetados, seqüela, atrofia e assimetria da paralisia.

*** Odds Ratio

área urbana, deve-se organizar imediatamente o bloqueio como uma campanha de vacinação. Uma vez que, as campanhas têm sido tradicionalmente planejadas e apoiadas do nível central para o nível local, muitas vezes o pessoal local espera o apoio do nível central, num processo que poder-se-ia chamar, na linguagem antropológica, de "representação". Assim, ao se classificar um caso de paralisia flácida aguda como um provável caso de poliomielite, os serviços de saúde locais acionam o nível central para as ações de bloqueio, identificados por meio da representação.

Isto faz com que o nível local se imobilize e aguarde uma resposta do nível central, que freqüentemente tenta esclarecer o caráter local da iniciativa de bloqueio. Isto, evidentemente, tem sérias consequiências para a interrupção imediatada cadeia de transmissão da doença.

Um segundo aspecto que nos parece relevante é o da tática de vacinação aplicada durante os bloqueios. Enquanto as campanhas são estruturadas com postos de vacinação previamente localizados em áreas estratégicas de modo a atingir um maior número de crianças, estas não chegam a atingir $100 \%$ dos grupos-alvo. O resíduo percentual das coberturas, seja de $10 \%$ ou $20 \%$, parece expressar a permanência de grupos não atingidos pelas campanhas, confina- dos a "bolsões" de suscetíveis e capazes de possibilitar a continuidade da transmissão do vírus.

No Brasil, se revermos as coberturas médias da vacinação antipólio por grandes regiões, constatamos que, embora atingindo-se e mantendo-se coberturas acima de $80 \%$, em algumas áreas do país os casos de poliomielite ocorridos em 1988 e 1989 sugerem que alguns "bolsões" de suscetíveis, em uma determinada densidade populacional, coincidem com o observado durante a erradicação da varíola.

Estes "bolsões", dificilmente atingidos pelas sucessivas campanhas por razões de várias ordens, só podem ser atingidos numa ação de bloqueio, cuja definição deve ser, ao nosso ver, distinta da de campanha, levando a vacinação a áreas não cobertas anteriormente e organizando uma mobilização da comunidade, de modo a incluir $100 \%$ dos grupos-alvo. Introduz-se a Vigilância Epidemiológica por municípios infectados, como ilustra a Figura 1. As estratégias para tal mobilização, desenvolvidas e acionadas a nível local por pessoal local, tornam as ações de bloqueio um instrumento fundamental para a erradicação da pólio, como o foi para a erradicação da varíola.

Neste contexto, propõe-se, a partir de 1989, um novo método para se eliminar a possibilida- 
de de existência daqueles "bolsões" de suscetíveis. É introduzido o conceito de "operação limpeza" - Mop-up, em inglês - que, desde implantado, tem resultado num impacto importante sobre a circulação do poliovírus selvagem.

FIGURA 1. Número de Municípios Infectados, América Latina, 1986-1990

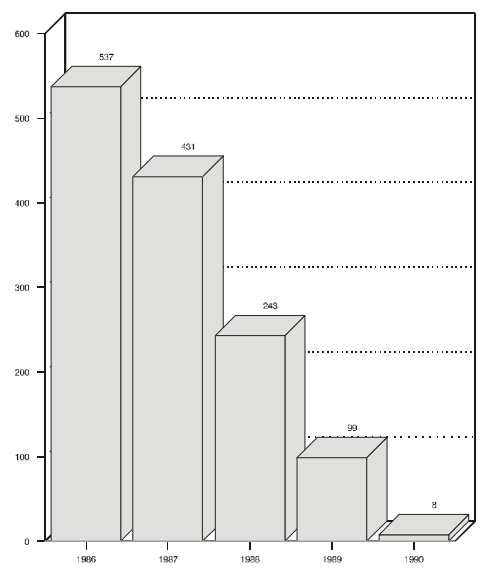

Fonte: Dados de 14.636 municípios - OPS.

A definição de "operação limpeza" é, em termos práticos, uma extensão do conceito de bloqueio; em outras palavras, é a ação de vacinar, casa a casa, todos os menores de cinco anos, em toda a extensão do município, onde se notificou um caso de paralisia flácida aguda em menores de 15 anos. Esta categoria operacional fez com que importantes grupos de suscetíveis fossem atingidos, grupos esses não atingidos por programas rotineiros de vacinação ou mesmo pelas campanhas maciças. Tal ação, acompa- nhada de um alerta e da intensificação da Vigilância Epidemiológica na área em ques-tão, tem demonstra- do ser eficaz em interromper a circulação do vírus, já que a observação das áreas tem constatado a não-existência de casos confirmados de poliomielite, apesar da detecção e da investigação cuidadosa de casos de paralisia flácida aguda.

\section{INDICADORES DA VIGILÂNCIA EPIDEMIOLÓGICA}

O que apresentamos a seguir é o estabelecimento de indicadores de vigilância epidemiológica no Programa da Poliomielite.
Como dizíamos, o processo de conhecimento da epidemiologia da doença leva, numa primeira etapa, à elaboração de conceitos e à tranformação dos mesmos em categorias operacionais, e, numa etapa concomitante, estabelece indicadores pelos quais avalia-se permanentemente, o desempenho do programa em termos de sua eficácia na interrupção da cadeia de transmissão do vírus.

$\mathrm{Na}$ fase atual, o programa de erradicação utiliza os seguintes indicadores:

- Taxa de notificação negativa semanal de casos de paralisia aguda e flácida de pelo menos $90 \%$ dos postos de notificação implantados;

- Taxa de notificação positiva de 1.0 caso por 100.000 habitantes menores de 15 anos (não incluídos os casos de paralisia facial periférica);

- Proporção de casos notificados de paralisia aguda e flácida investigados em $\mathbf{4 8}$ horas;

- Proporção de casos notificados que tiveram duas amostras de fezes colhidas até duas semanas após o início do déficit motor;

- Proporção de casos que tiveram investigação de 5 contatos no mínimo;

- Proporção de casos que tiveram operação limpeza;

- Proporção de casos com revisita de avaliação dentro de 72 dias.

O desempenho destes indicadores traduz o avanço do programa, bem como áreas críticas que se deve melhorar, de modo a evidenciar a interrupção da circulação do vírus selvagem.

Cumpre ressaltar neste ponto, que as metas apresentadas foram fixadas por uma comissão independente para a certificação da erradicação do poliovírus selvagem na região das Américas.

A Figura 2 apresenta os últimos casos confirmados de poliomielite nas Américas durante 1990 e 1991, refletindo a ausência de casos associados ao poliovírus selvagem em vastas áreas do continente.

Um último aspecto da vigilância epidemiológica específica da pólio é o monitoramento da circulação do poliovírus selvagem no meio ambiente.

Ao contrário da varíola, a infecção pelo poliovírus é, na grande maioria dos casos, 


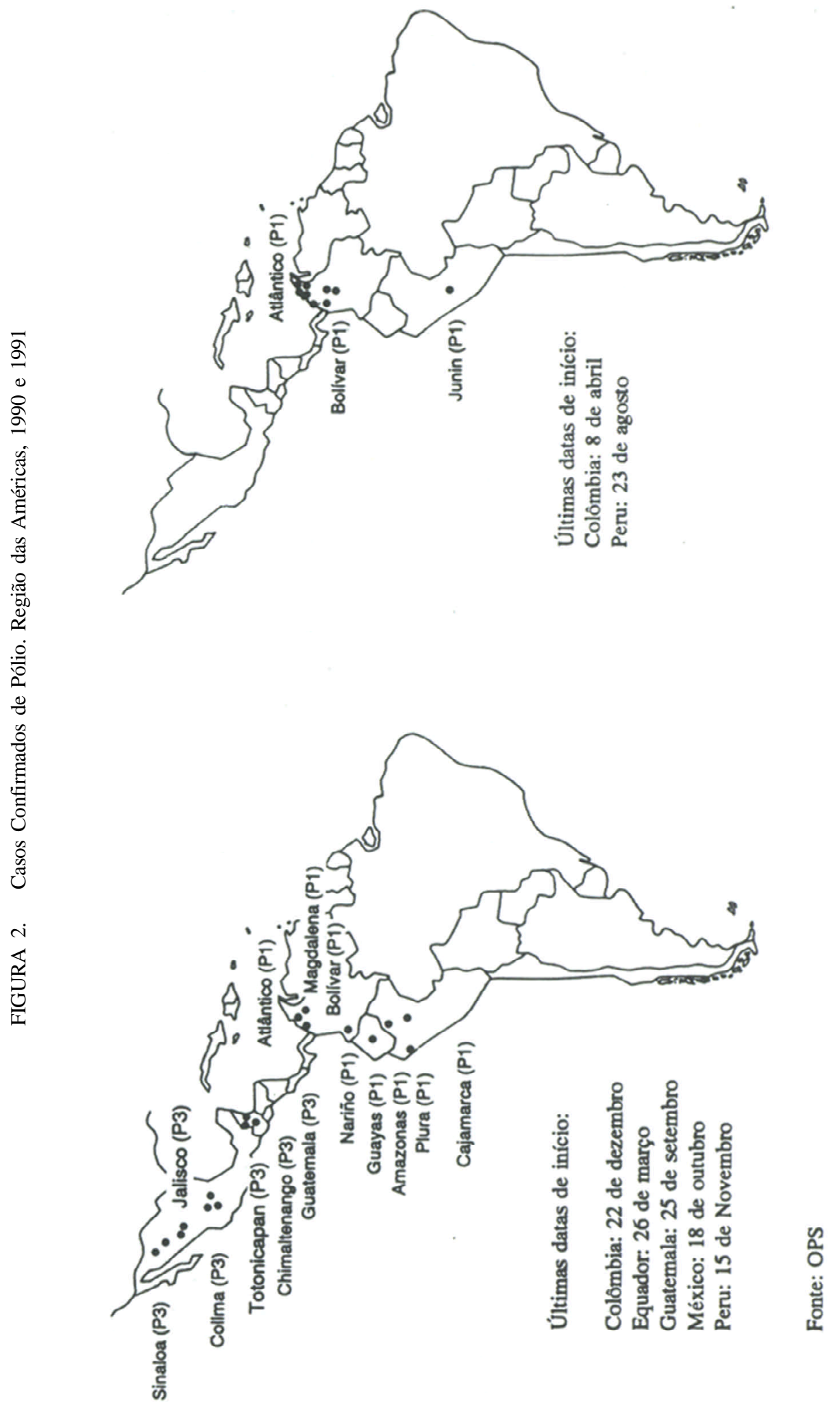


clinicamente inaparente. Estima-se que $1 \%$ das infecções desenvolvem a paralisia, fazendo com que a vigilância epidemiológica do poliovírus, na ausência de outro sinal clínico, seja exercida também no meio ambiente.

A eliminação do poliovírus - vacinal ou selvagem - pelas fezes de pessoas infectadas faz com que os esgotos e valas de dejetos sejam os mais importantes veiculadores do vírus.

Portanto, a ausência de casos de paralisia flácida aguda associada a poliovírus não é suficiente para se afirmar que a circulação do vírus cessou em uma região, sendo necessário, neste ponto, o monitoramento da circulação do vírus selvagem no meio ambiente, monitoramento que se realiza através de métodos específicos e com periodicidade determinada. A especificidade dos métodos laboratoriais para isolamento e diferenciação intratípica do poliovírus, sobretudo a técnica de PCR (Polymerase Chain Reaction), permite, hoje, a detecção do poliovírus selvagem caso este esteja circulante no meio ambiente.

O critério para a utilização destes métodos como instrumento complementar à Vigilância Epidemiológica leva em consideração as áreas de risco de circulação do poliovírus, isto é, áreas em que houve isolamento de vírus de casos ou de contatos nos últimos dois anos, áreas com baixo índice de notificação de parali-sia flácida aguda, ou áreas com coberturas vacinais insuficientes.

\section{CONCLUSÕES}

Os métodos de vigilancia epidemiológica desenvolvidos nos Programas de Erradicação da Varíola e da Poliomielite colocam à disposição da Saúde Pública, hoje, os instrumentos necessários para que outras doenças imunopreveníveis sejam erradicadas ou, no mínimo, controladas a níveis suficientemente baixos para que deixem de ser um problema.

Um ponto de fundamental importância - não abordado neste trabalho por situar-se fora da ótica técnico-científica que nos propusemos abordar - é o fato dos conceitos, métodos e estratégias de vigilância epidemiológica terem tido como condição sine qua non de seu desen- volvimento o forte e continuado apoio político, tanto dos governos quanto das organizações envolvidas no apoio aos programas de imunização. Sem a decisão política definitiva e a alocação de recursos financeiros, embora modestos em termos de custo-benefício, estaríamos hoje provavelmente o ainda assistindo a epidemias de varíola.

Finalmente, há evidências de que os programas de imunização e, dentro deles, o desenvolvimento dos sistemas de vigilância epidemiológica têm contribuído de modo importante para o fortalecimento dos sistemas locais de saúde e dos Programas de Atenção Primária. Hoje, o Programa de Eliminação do Tétano Neonatal tem servido como indicador dos Programas de Atenção Materno-Infantil em vastas regiões do mundo. Do mesmo modo, assiste-se hoje, na região das Américas, a importantes passos para o controle e eliminação do sarampo. Mais uma vez, os conceitos e métodos a que nos referimos são frutos da prática, fazendo de uma doença transmissível uma vez mais um assunto da história.

\section{RESUMO}

VERANI, J. F. S.; MARANHÃO, E. P. \& LAENDER, F. Desenvolvimento dos Sistemas de Vigilância Epidemiológica da Varíola e da Poliomelite: A Transformação de Conceitos em Categorias Operacionais. Cad.

Saúde Públ., Rio de Janeiro, 9 (1): 2838, jan/mar, 1993.

O artigo descreve o processo através do qual alguns conceitos de vigilância epidemiológica são elaborados e transformados em categorias operacionais, constituindo, assim, o Sistema de Vigilância Epidemiológica de algumas doenças transmissíveis.

A descrição do modo pelo qual alguns conceitos e categorias epidemiológicas foram sendo elaborados enfoca o Programa de Erradicação da Varíola e, mais recentemente, o Programa de Erradicação do Vírus Selvagem da Poliomielite.

Conceitos como os de bloqueio e notificação cruzada, bem como as definições de casos, são descritos de modo a apresentar sua 
transformação em categorias operacionais no contexto de ações que, articuladas num sistema de vigilância epidemiológica, são capazes de controlar e erradicar algumas doenças imunopreveníveis, como a varíola, a poliomielite e o sarampo.

Finalmente, vale ressaltar que a descrição de que trata este artigo baseia-se nas observações diretas dos autores enquanto participantes no Programa de Erradicação da Varíola em Bangladesh e na Somália, e no Programa de Erradicação da Poliomielite, na região das Américas.

Palavras-C have: Vigilância Epidemiológica; Vacinação; Poliomelite; Varíola; Epidemiologia

\section{REFERÊNCIAS BIBLIOGRÁFICAS}

ANDRUS, J.; DE QUADROS, C. \& OLIVE, J., 1991. Análisis de Sensibilidad y Especificidad de Criterios Operativos para el Tamizado de Casos de Parálisis Flaccida Aguda. Washington: Organización Panamericana de la Salud. (Mimeo.)

ARITA, I., 1986. Impact of population density on immunization programs. Journal of Hygiene, 96: 459-466.

DE QUADROS, C., 1991. Eradication of poliomyelitis: progress in the Americas. Pediatric Infectious Disease Journal, 10: 222-229.
FENNER, S.; HENDERSON, D. A.; ARITA, I.; JEZEK, Z. \& LADNYI, I. 1988. Smallpox and its Eradication. Geneva: World Health Organization.

HENDERSON, D. A., 1978. Smallpox: epitaph for a killer ? National Geographic Magazine, 154: 796-805.

OPS (Organización Panamericana de La Salud), 1991. Boletin Informativo PAI, $n^{\circ} 4: 1$. Washington: Organizácion Panamericana de la Salud. , 1988. VI Reunión del Grupo Tecnico Asesor del P.A.I. y la Erradicación de la Polio Informe Final. Buenos Aires. (Mimeo.)

OPAS (Organização Pan-Americana da Saúde) \& SNABS (Ministério da saúde do Brasil), 1986. Avaliação da Cobertura Vacinal. Arapiraca, Alagoas. (Mimeo.)

PLOTKIN, S. \& MORTIMER, E., 1988. Vaccines. Philadelphia: W. B. Saunders.

RISI, J., 1985. El control de la poliomielitis en el Brasil. In: Simposio Internacional sobre el Control de la Poliomielitis, Publicação Científica $\mathrm{n}^{\mathrm{o}}$ 484, pp. 147-151, Washington: Organización Pana-mericana de la Salud.

VERANI, J. F. 1991. A Vigilância Epidemiológica na Erradicação de Doenças: 0 Caso da Varíola e da Poliomielite. Tese de Mestrado, Rio de Janeiro: Escola Nacional de Saúde Pública. 